\title{
Parasitic Leiomyomas Following Laparoscopic Myomectomy
}

\author{
Nisse V. Clark, MD, Mateo G. Leon, MD, Colleen M. Feltmate, MD, Sarah L. Cohen, MD \\ Department of Obstetrics and Gynecology, Brigham and Women's Hospital, Boston, Massachusetts (Drs. Clark, Feltmate, \\ and Cohen). \\ Department of Obstetrics and Gynecology, University of Texas Health-McGovern Medical School, Houston, Texas \\ (Dr. Leon).
}

\begin{abstract}
Introduction: Parasitic leiomyoma is a rare condition that may be spontaneous or iatrogenic in origin. Laparoscopic uterine surgery and tissue morcellation are procedures that may lead to the development of parasitic leiomyoma.

Case Description: We report the case of a 36-year-old woman with a history of a laparoscopic myomectomy and uncontained power morcellation who presented to our institution 6 years later with 2 large parasitic fibroids together weighing over $1 \mathrm{~kg}$. We additionally present a review of the literature on development of parasitic leiomyoma after myomectomy, summarizing 35 published cases in addition to our own.
\end{abstract}

Conclusion: Parasitic leiomyoma is estimated to occur after 0.20 to $1.25 \%$ of laparoscopic myomectomies, and is diverse in it's presenting symptoms and surgical findings. Tissue morcellation is suspected to be a risk factor in the development of this condition.

Key Words: Parasitic leiomyomas, Myomectomy, Uncontained morcellation.

Citation Clark NV, Leon MG, Feltmate CM, Cohen SL. Parasitic leiomyomas following laparoscopic myomectomy. CRSLS e2017.00018. DOI: 10.4293/CRSLS.2017.00018.

Copyright (C) 2017 by SLS, Society of Laparoendoscopic Surgeons. This is an open-access article distributed under the terms of the Creative Commons Attribution-Noncommercial-ShareAlike 3.0 Unported license, which permits unrestricted noncommercial use, distribution, and reproduction in any medium, provided the original author and source are credited.

Disclosures: none reported.

Address correspondence to: Nisse V. Clark, MD, Brigham and Women's Hospital Department of OBGYN, 75 Francis Street, Boston, MA 02115. Telephone: 617-525-8582, Fax: 617-975-0900, E-mail: nvclark@partners.org

\section{INTRODUCTION}

Parasitic leiomyoma is a rare type of extrauterine fibroid that has been described in the literature since $1909 .{ }^{1} \mathrm{Al}-$ though little is known about the incidence and risk factors of this condition, it is presumed to originate from pedunculated fibroids that spontaneously detach from the uterus and obtain an alternative blood supply from adjacent organs. ${ }^{2,5}$ In recent decades, however, an increase in the development and use of minimally invasive techniques has led to a potential iatrogenic origin of parasitic leiomyoma. The inadvertent dissemination of tissue fragments during laparoscopic surgical maneuvers, tissue manipulation, and extraction procedures creates the potential for fibroids to parasitize to extrauterine sites. ${ }^{3}$ The first reported case of an iatrogenic parasitic fibroid was in 1997 and described a parasitic fibroid located in an abdominal wall port site months after a laparoscopic myomectomy involving the use of power morcellation. ${ }^{4}$ Since this first case was described, further reports of similar findings have been documented. We present a case of parasitic leiomyoma after a laparoscopic myomectomy, as well as a literature review on the subject.

\section{CASE REPORT}

A 36-year-old woman, gravida 2 para 2, was referred for surgical removal of symptomatic parasitic fibroids. Her medical history was notable for symptomatic uterine fibroids prompting a robot-assisted laparoscopic myomectomy 6 years before presentation. This initial surgery was 
performed for a dominant $8-\mathrm{cm}$ posterior intramural fibroid and was complicated by an estimated blood loss of $1500 \mathrm{~mL}$. The fibroid was extracted in stages using open power morcellation and taking care to remove any residual fragments from the abdominal cavity. The patient required an intraoperative blood transfusion and postoperative admission to the intensive care unit. She was discharged home on postoperative day 2 .

The patient became pregnant 3 years later and underwent a primary cesarean section at which time 2 parasitic fibroids, one $10 \mathrm{~cm}$ in diameter and the other $4 \mathrm{~cm}$ in diameter, were found attached to the abdominal wall. Both fibroids were pedunculated and excised by sutureligating their vascular stalks to the anterior abdominal wall. The patient again became pregnant the following year, and a $12.5-\mathrm{cm}$ left pelvic fibroid was noted on in early ultrasonography. At the time of repeat cesarean section, the fibroid had grown to $15 \mathrm{~cm}$ and was found to extend to the left upper quadrant with suspected attachments to the bowel. The decision was made not to remove the fibroid at that time. A subsequent postpartum magnetic resonance image identified two parasitic fibroids: one in the left pelvis, measuring $11.2 \times$ $9.4 \times 16.3 \mathrm{~cm}$, and the other between the right lobe of the liver and right upper renal pole, measuring $4.1 \times$ $3.8 \times 4.5 \mathrm{~cm}$ (Figures 1 and 2 ).

The patient was then referred to our department for surgical removal of the parasitic fibroids. Upon laparoscopic survey, a large fibroid was found enwrapped in the sigmoid mesocolon, and the decision was made to convert to a laparotomy. The parasitic fibroid measured $17.5 \times 13 \times$ $10.5 \mathrm{~cm}$ and was retroperitoneal, with its vascular supply derived from the sigmoid mesenteric and left adnexal vessels. The mass was distinct from a normal-appearing uterus. A $5.2 \times 4.3 \times 3.2 \mathrm{~cm}$ parasitic fibroid was also identified in the hepatorenal fossa. Both of these masses were carefully separated from the adjacent organs and excised. The patient did well after surgery and was discharged home on postoperative day 3. Final pathology returned with benign leiomyomas with an aggregate weight of $1036 \mathrm{~g}$ (Figures 3-7).

\section{REVIEW OF THE LITERATURE}

Parasitic leiomyoma after myomectomy is a rare condition that is increasingly reported in the literature. We conducted a literature review by searching PubMed, Google Scholar, and Cochrane databases, using the terms leiomyoma OR fibroid OR uterine myoma OR abdominal myomectomy OR laparoscopic myomec-

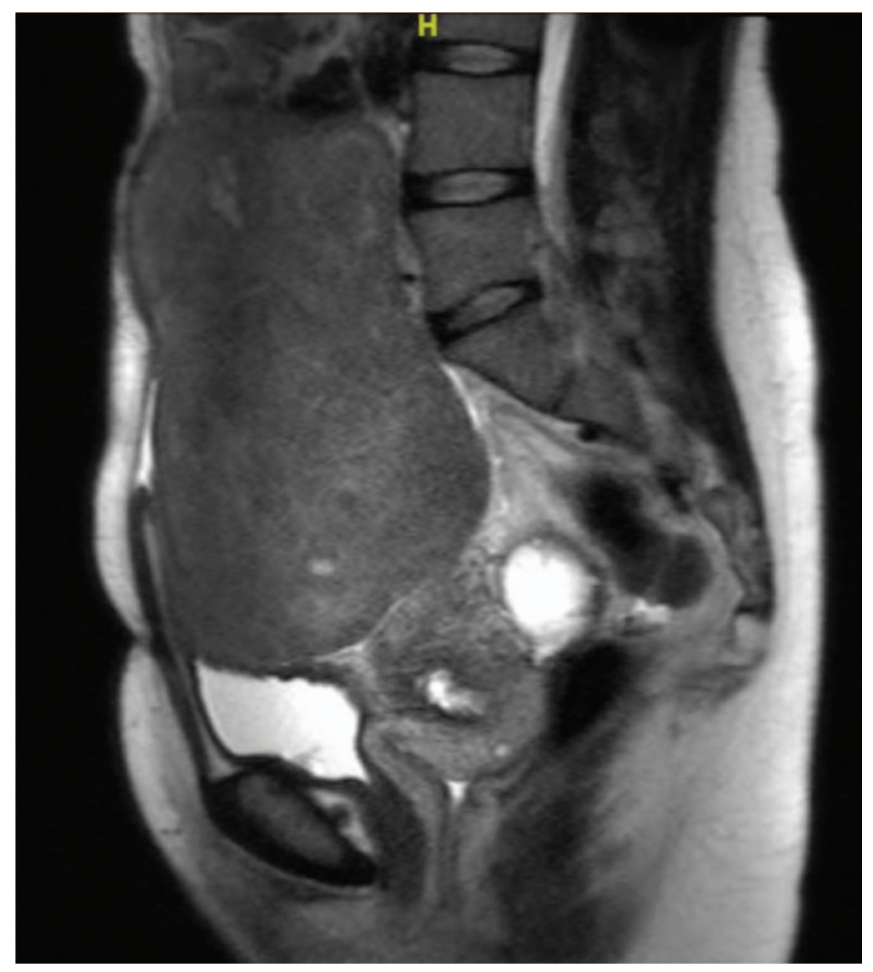

Figure 1. Sagittal MRI view of the left pelvic parasitic fibroid.

tomy AND parasitic. We excluded reports of other types of extrauterine leiomyoma (disseminated peritoneal leiomyomatosis, benign metastasizing leiomyoma, and intravenous leiomyoma), patients without prior surgery, patients with a prior hysterectomy, non-English articles, abstracts only, or histopathology not consistent with leiomyoma.

Table 1 summarizes the clinical features of 35 previously published cases, in addition to our own. The patients' ages ranged from 24 to 57 years, with most in their reproductive years. The majority (83\%) had a myomectomy performed by laparoscopic approach; 93\% involved morcellation. Review of the case reports did not specify whether morcellation was open or contained; however, the lack of specification and years of publication suggest that most were performed in an open, not closed, fashion. Six patients had undergone an abdominal myomectomy without morcellation, emphasizing that morcellation is not the only risk factor for parasitic leiomyoma. Common signs and symptoms in the reviewed cases included pain (40\%) and bulk symptoms, such as a palpable mass, pressure, or abdominal distension (20\%). Parasitic leiomyoma can also be asymptomatic, as was the case in 31\% of patients in our review, the lesions were diagnosed within 1 month and up to 17 years after myomectomy. Review of 


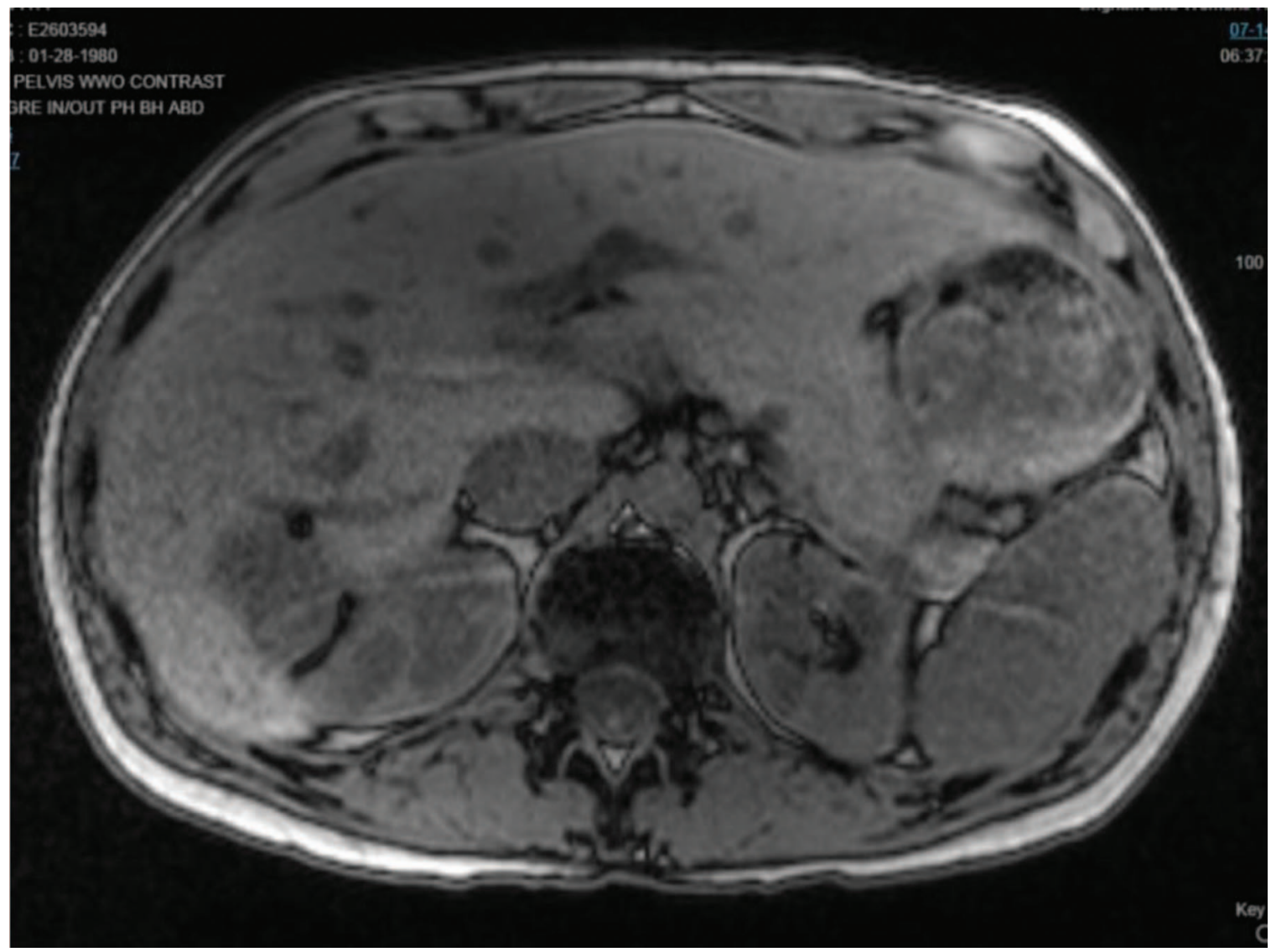

Figure 2. Axial MRI view of the right hepatorenal parasitic fibroid.

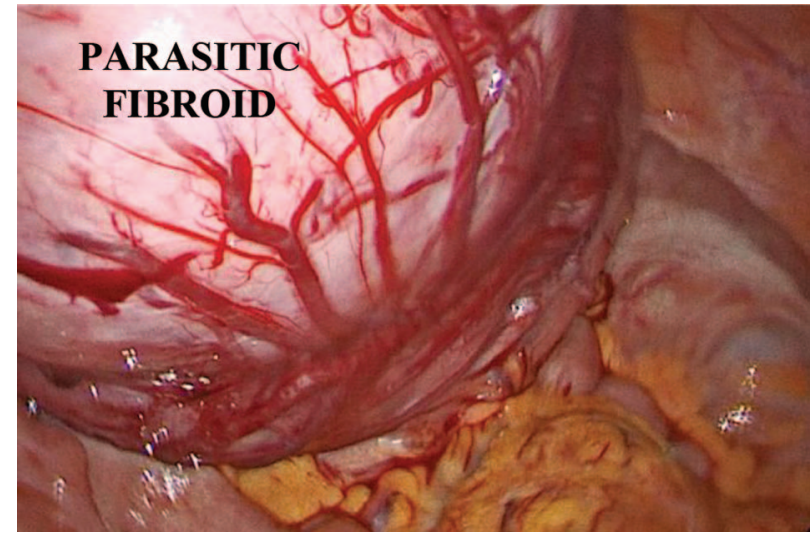

Figure 3. Large left pelvic parasitic fibroid enwrapped in the sigmoid mesocolon.

all the case reports revealed a range of 1 to 9 parasitic leiomyomas per patient, ranging in size from 1 to $23 \mathrm{~cm}$. Parasitic leiomyomas were discovered in various locations throughout the abdominal cavity, including the retroperitoneum.

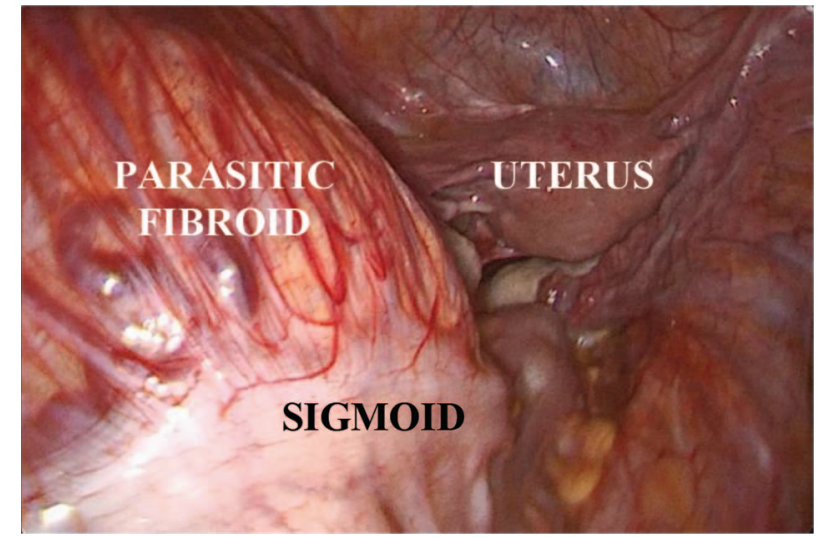

Figure 4. Parasitic fibroid enwrapped in sigmoid colon. The uterus is visible in the background.

\section{DISCUSSION}

Parasitic leiomyoma is estimated to occur after 0.20 to $1.25 \%$ of laparoscopic myomectomies and 0.12 to $0.95 \%$ of all laparoscopic uterine surgeries that involve morcellation. ${ }^{5}$ 


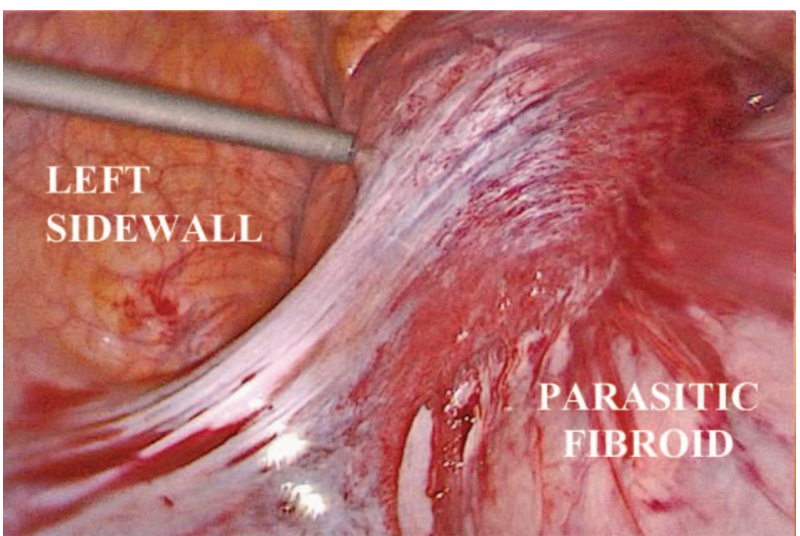

Figure 5. Vascular attachments of the left pelvic parasitic fibroid to the left side wall.

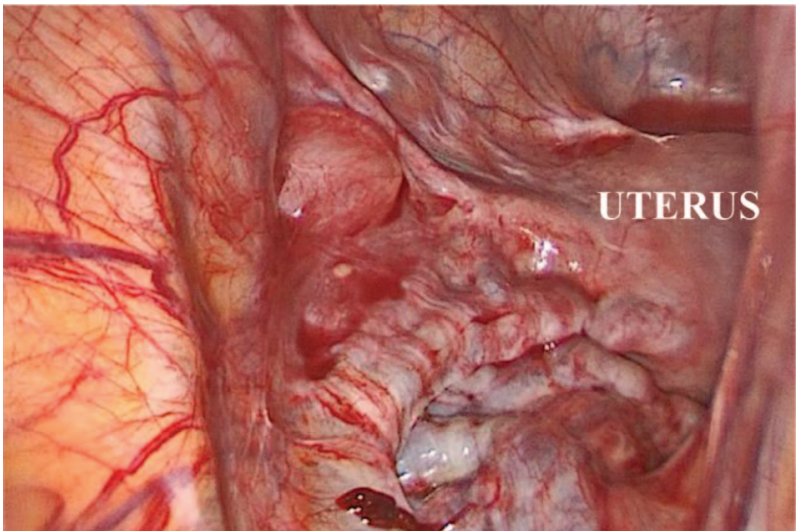

Figure 6. Dilated left adnexal vessels supplying the left pelvic parasitic fibroid.

Iatrogenic parasitic leiomyoma is thought to develop when dispersed tissue fragments obtain neovascularization to adjacent organs, although the exact mechanism of their localization and ability to thrive is still unknown. Most reviews have found a greater incidence of parasitic leiomyoma after myomectomy compared with hysterectomy (59-62.5\% compared to $29.6-41 \%$ of iatrogenic cases). ${ }^{6,7}$ Their development is multifactorial and is likely related to greater use of morcellation after laparoscopic myomectomy vs hysterectomy, the younger age of patients undergoing myomectomy, and the potential added risk of fibroid enucleation causing dissemination of tissue fragments.

It is important to note that parasitic leiomyoma can also develop in a patient who has not undergone uterine surgery. This phenomenon is thought to occur when a pedunculated fibroid spontaneously detaches from the uterus. Conditions that restrict the blood supply to the uterus, such as gonadotropin-releasing hormone (GnRH)

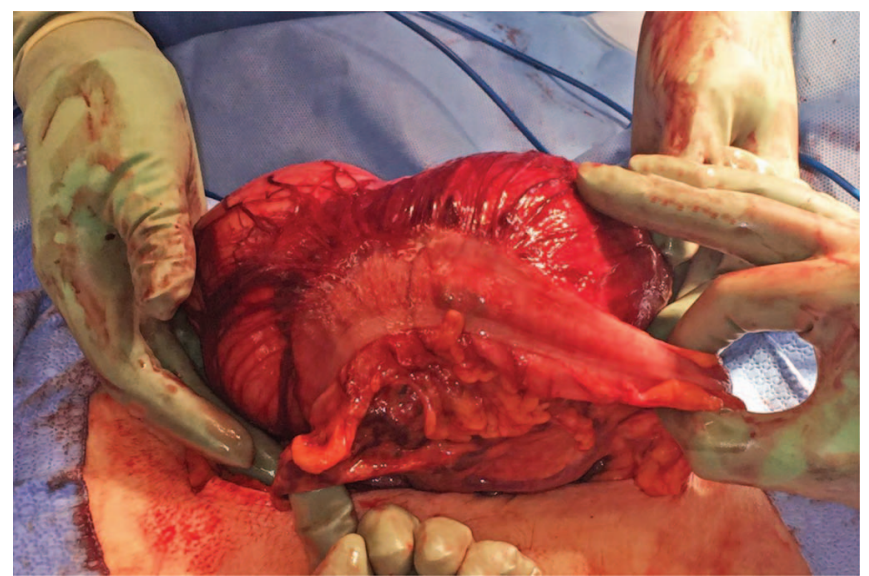

Figure 7. Left pelvic parasitic fibroid and sigmoid colon as seen upon conversion to laparotomy.

agonists, radiofrequency ablation, and uterine artery embolization may be associated with this process, as pedunculated fibroids seek an alternate blood supply. ${ }^{8}$ Whether iatrogenic or sporadic in origin, steroid hormones, and growth factors are thought to contribute to the formation of parasitic leiomyoma. ${ }^{9}$ Correspondingly, most cases are found in women of reproductive age. A few have also been described in postmenopausal patients receiving hormone replacement therapy. ${ }^{6}$

Parasitic leiomyoma is often diagnosed as an incidental finding on clinical or surgical evaluation. It is estimated that $25 \%$ of all patients with parasitic fibroid are asymptomatic, although this value is likely underestimated, as patients without symptoms do not present for evaluation. ${ }^{6}$ When symptoms do occur, abdominal or pelvic pain is the most common (49\%), followed by a mass sensation in abdomen or pelvis (11\%), bleeding (10\%), and abdominal distention (5\%), among other symptoms (16\%). 9,10

Parasitic leiomyoma is distinct from other extrauterine leiomyomas, such as disseminated parasitic leiomyomatosis (DPL). DPL is a rare disease characterized by multiple nodules on the omentum and peritoneal surfaces similar to carcinomatosis. ${ }^{11}$ The etiology is unclear, but theories include the hormonal response of subperitoneal mesenchymal stem cells to undergo metaplasia and the proliferation of benign smooth muscle cells related to genetic alterations. ${ }^{12}$ A potential iatrogenic origin is also cited, with many cases occurring after laparoscopic morcellation, especially myomectomy. Benign metastasizing leiomyoma and intravenous leiomyoma are even rarer and have no known association with laparoscopic surgery. 


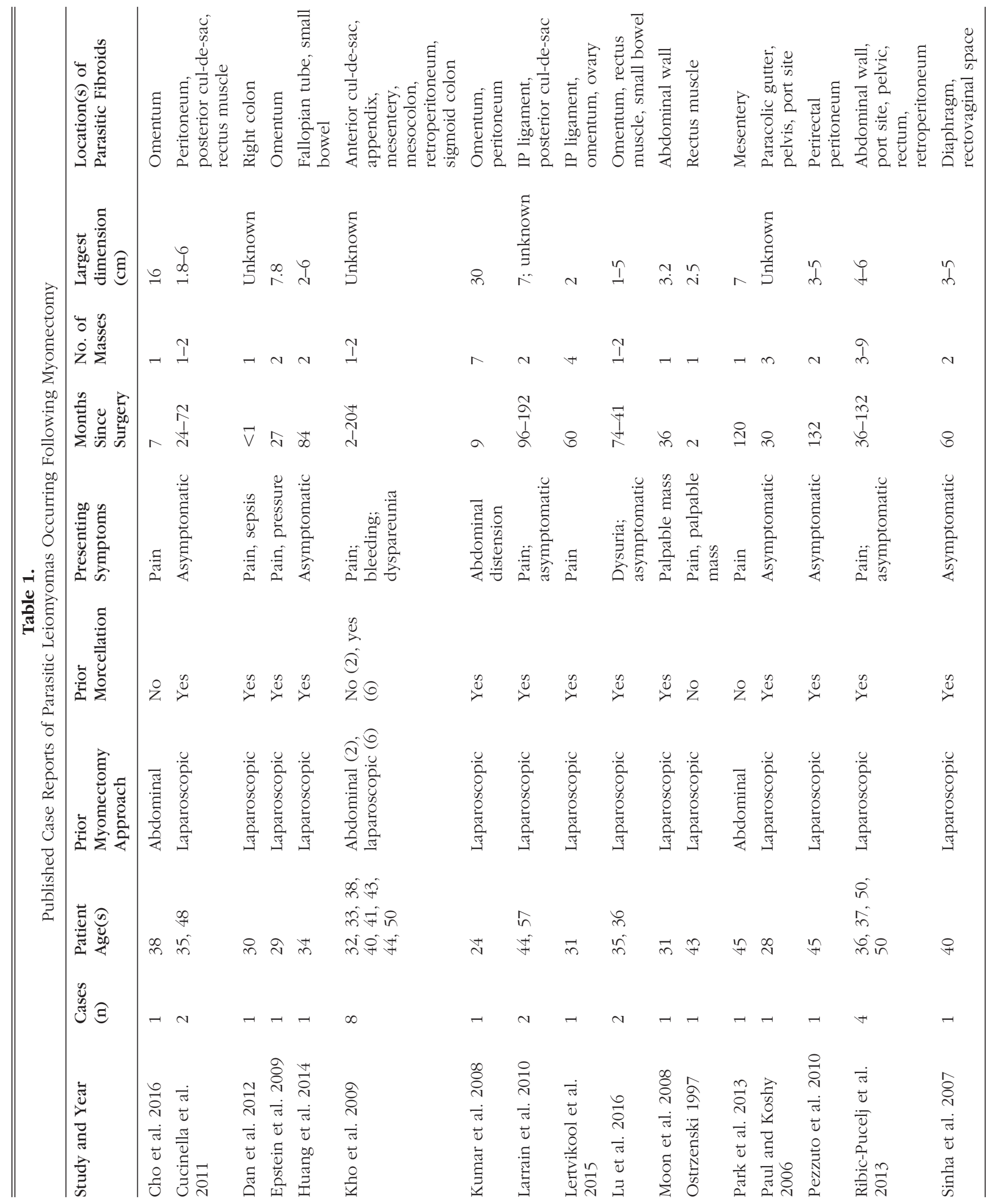




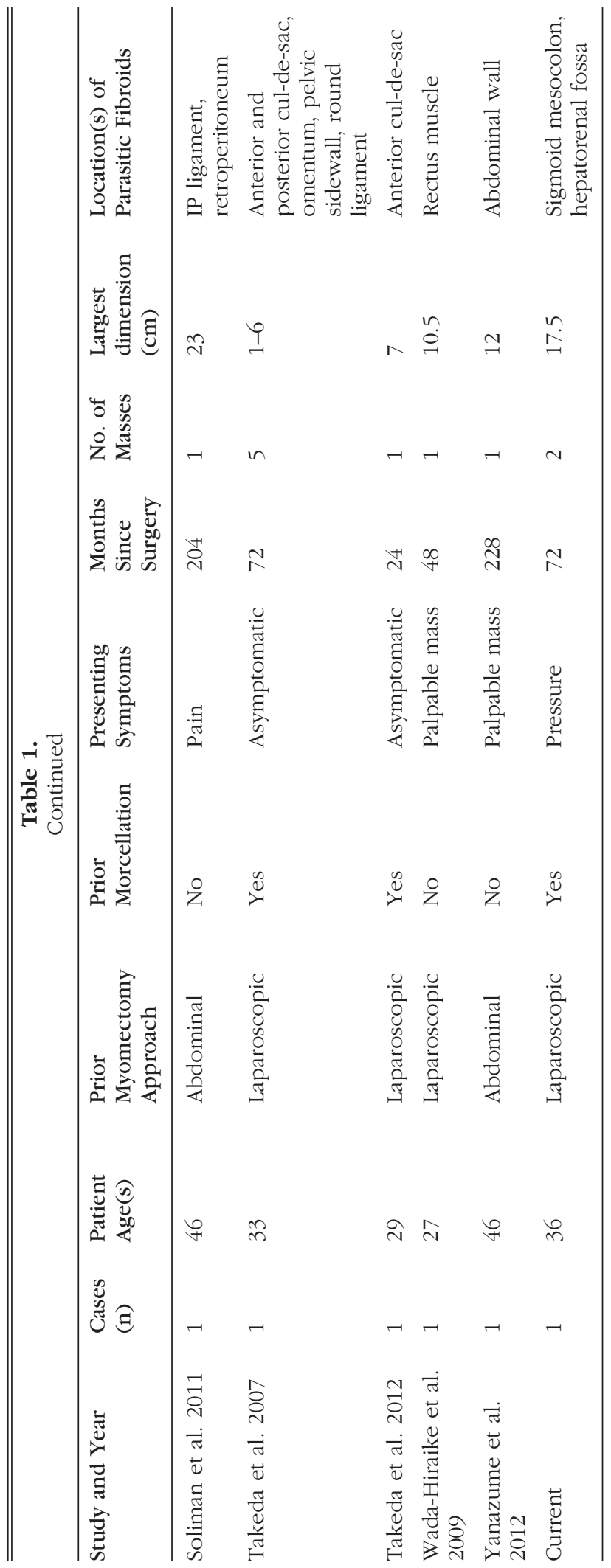

Parasitic leiomyoma is the most commonly reported benign sequela of tissue morcellation, with a prevalence of up to $1 \%$ of cases.5,12 This rate is much higher than the prevalence of uterine sarcoma, the focus of the U.S. Food and Drug Administration's statement discouraging the use of laparoscopic power morcellators in 2014. ${ }^{13}$ New techniques have emerged to improve the safety of tissue extraction including manual or power morcellation within a containment bag. ${ }^{14,15}$ This technique reduces the potential for tissue spillage and may reduce the risk of parasitic leiomyoma or malignant tissue dissemination. Other techniques that may reduce the likelihood of disseminated tissue includes maintaining an accurate fibroid count during laparoscopic myomectomy and carefully removing any dispersed tissue fragments during uterine surgery. Further studies are needed to assess the benefits of these techniques.

\section{CONCLUSION}

Parasitic leiomyoma may be sporadic or iatrogenic in origin. Laparoscopic myomectomy with tissue morcellation is a major risk factor for this condition. Careful attention to complete removal of all fibroids and tissue fragments, in addition to the use of a contained morcellation system, may reduce the risk of subsequent parasitic leiomyoma. It is important to counsel patients on the potential for this condition and to maintain an index of suspicion when a patient presents with new clinical symptoms after uterine surgery.

\section{References:}

1. Kelly HA, Cullen TS. Myomata of the Uterus. Philadelphia, PA: WB Saunders; 1909, p 13.

2. Brody S. Parasitic fibroids. Am J Obstet Gynecol. 1953;65: $1354-1356$.

3. Nezhat C, Kho K. Iatrogenic myomas: new class of myomas? J Minim Invasive Gynecol. 2010;17:544-550.

4. Ostrzenski A. Uterine leiomyoma particle growing in an abdominal-wall incision after laparoscopic retrieval. Obstet $G y$ necol. 1997;89:853-854.

5. Van der Meulen JF, Pijnenborg JMA, Boomsma CM, Verberg MFG, Geomini PMAJ, Bongers MY. Parasitic myoma after laparoscopic morcellation: a systematic review of the literature. BJOG. 2016;123:69-75.

6. Leren V, Langebrekke A, Qvigstad E. Parasitic leiomyomas after laparoscopic surgery with morcellation. Acta Obstet Gynecol Scand. 2012;91:1233-1236. 
7. Pereira N, Buchanan TR, Wishall KM, et al. Electric morcellation-related reoperations after laparoscopic myomectomy and nonmyomectomy procedures. J Minim Invasive Gynecol. 2015; 22:163-176.

8. Lete I, Gonzalez J, Ugarte L, et al. Parasitic leiomyomas: a systematic review. Eur J Obstet Gynecol Reproduct Biol. 2016; 203:250-259.

9. Rabischong B, Beginot M, Compan C, et al. Long-term complication of laparoscopic uterine morcellation: iatrogenic parasitic myomas. J Gynecol Obstet Biol Reprod (Paris). 2013;42:577-584.

10. Pezzuto A, Pontrelli G, Ceccaroni M, Ferrari B, Nardelli GB, Minelli L. Case report of asymptomatic peritoneal leiomyomas. Eur J Obstet Gynecol Reprod Biol. 2010;148:205-206.

11. Al-Talib A, Tulandi T. Pathophysiology and possible iatrogenic cause of leiomyomatosis peritonealis disseminate. Gynecol Obstet Invest. 2010;69:239-244.

12. Tulandi T, Leung A, Jan N. Nonmalignant sequelae of unconfined morcellation at laparoscopic hysterectomy or myomectomy. J Minim Invasive Gynecol. 2016;23:331-7.

13. FDA. Laparoscopic uterine power morcellation in hysterectomy and myomectomy: FDA Safety Communication, 2014. Available at http://www.fda.gov/medicaldevices/safety/alertsandnotices/ucm393576.htm. Accessed November 27, 2016.

14. Cohen SL, Hariton E, Afshar Y, Siedhoff MT. Updates in uterine fibroid tissue extraction. Curr Opin Obstet Gynecol. 2016; 28:277-282.

15. Srouji SS, Kaser DJ, Gargiulo AR. Techniques for contained morcellation in gynecologic surgery. Fertil Steril. 2015;103:34.

16. Cho IA, Baek JC, Park JK, et al. Torsion of a parasitic myoma that developed after abdominal myomectomy. Obstet Gynecol Sci. 2016;59:75-78.

17. Cucinella G, Granese R, Calagna G, Somigliana E, Perino A. Parasitic myomas after laparoscopic surgery: an emerging complication in the use of morcellator? Description of four cases. Fertil Steril. 2011;96:90-96.

18. Dan D, Harnanan D, Hariharan S, Maharaj R, Hosein I, Naraynsingh V. Extrauterine leiomyomata presenting with sepsis requiring hemicolectomy. Rev Bras Ginecol Obstet. 2012;34:285-289.

19. Epstein JH, Nejat EJ, Tsai T. Parasitic myomas after laparoscopic myomectomy: case report. Fertil Steril. 2009;91:13-14.

20. Huang PS, Chang WC, Huang SC. Iatrogenic parasitic myoma: a case report and review of the literature. Taiwan J Obstet Gynecol. 2014;53:392-396.

21. Kho KA, Nezhat C. Parasitic myomas. Obstet Gynecol. 2009; 114:611-615.

22. Kumar S, Sharma JB, Verma D, Gupta P, Roy KK, Malhotra N. Disseminated peritoneal leiomyomatosis: an unusual complica- tion of laparoscopic myomectomy. Arch Gynecol Obstet. 2008; 278:93-95.

23. Larrain D, Rabischong B, Khoo CK, Botchorishvili R, Canis M, Mage G. Iatrogenic parasitic myomas: unusual late complications of laparoscopic morcellation procedures. J Minim Invasive Gynecol. 2010;17:719-724.

24. Lertvikool S, Huang KG, Adlan AS, Chua AAA, Lee CL. Parasitic leiomyoma after laparoscopic myomectomy. Gyn Min Invas Ther. 2015;4:98-100.

25. Lu B, Xu J, Pan Z. Iatrogenic parasitic leiomyoma and leiomyomatosis peritonealis disseminata following uterine morcellation. J Obstet Gynaecol Res. 2016;42:990-999.

26. Moon HS, Koo JS, Park SH, Park GS, Choi JG, Kim SG. Parasitic leiomyoma in the abdominal wall after laparoscopic myomectomy. Fertil Steril. 2008;90:1201-1202.

27. Park DS, Shim JY, Seong SJ, Jung YW. Torsion of parasitic myoma in the mesentery after myomectomy. Eur J Obstet Gynecol Reprod Biol 2013;169:414-415.

28. Paul PG, Koshy AK. Multiple peritoneal parasitic myomas after laparoscopic myomectomy and morcellation. Fertil Steril. 2006;85:492-493.

29. Ribic-Pucelj M, Cvjeticanin B, Salamun V. Leiomyomatosis peritonealis disseminate as a possible result of laparoscopic myomectomy: report of four cases. Gynecol Surg. 2013;10:253-256.

30. Sinha R, Hegde A, Mahajan C. Parasitic myoma under the diaphragm. J Minim Invasive Gynecol 2007;14:1.

31. Soliman AA, Elsabaa B, Hassan N, Sallam H, Ezzat T. Degenerated huge retroperitoneal leiomyoma presenting with sonographic features mimicking a large uterine leiomyoma in an infertile woman with a history of myomectomy: a case report. J Med Case Rep. 2011;5:578.

32. Takeda A, Mori M, Sakai K, Mitsui T, Nakamura H. Parasitic peritoneal leiomyomatosis diagnosed 6 years after laparoscopic myomectomy with electric tissue morcellation: report of a case and review of the literature. J Minim Invasive Gynecol. 2007;14: $770-775$.

33. Takeda A, Imoto S, Mori M, et al. Rapid growth of parasitic myoma in early pregnancy: previously undescribed manifestation of a rare disorder after laparoscopic-assisted myomectomy. Eur J Obstet Gynecol Reproduct Biol. 2012;162117-118.

34. Wada-Hiraike O, Yamamoto N, Osuga Y, Yano T, Kozuma S, Taketani Y. Aberrant implantation and growth of uterine leiomyoma in the abdominal wall after laparoscopically assisted myomectomy. Fertil Steril. 2009;92:e13-e15.

35. Yanazume S, Tsuji T, Yoshioka T, Yamasaki H, Yoshinaga $\mathrm{M}$, Douchi T. Large parasitic myomas in abdominal subcutaneous adipose tissue along a previous myomectomy scar. $J$ Obstet Gynaecol Res. 2012;38:875-879. 